\title{
Gordon Scott Fulcher: Renaissance man of glass science
}

\author{
John C. Mauro* \\ Science and Technology Division, Corning Incorporated, Corning, NY, USA
}

\section{Edited by:}

Morten M. Smedskjaer, Aalborg

University, Denmark

\section{Reviewed by:}

Francisco Muñoz, Consejo Superior de Investigaciones Cientificas, Spain Matthieu Micoulaut, Université Pierre et Marie Curie, France

${ }^{*}$ Correspondence:

John C. Mauro, SP-FR-05, Corning,

NY 14831, USA

e-mail:mauroj@corning.com
To a glass scientist, the name "Fulcher" conjures images of viscosity vs. temperature diagrams for glass-forming liquids. Indeed, Gordon Fulcher's seminal 1925 publication, in which he proposed his three-parameter model of viscosity, is one of the most significant and influential papers ever published in the field of glass science. Fulcher developed this equation during the early part of his 14-year career at Corning Glass Works (1920-1934). However, Fulcher's work in viscosity represents a small fraction of his highly diverse and accomplished career, which included pioneering the field of electrocast ceramics and developing the modern system of scientific abstracting that is still in use today. Fulcher also had a keen interest in social and economic problems, and his latter research focused heavily on the field of metacognition, i.e., the process of thinking.

Keywords: glass, viscosity, history, ceramics, metacognition

\section{INTRODUCTION}

This may be the most important proposition revealed by history:

"At the time, no one knew what was coming."

$$
\text { - Haruki Murakami, } 1 \text { Q84 }
$$

In 1932, W. H. Zachariasen began his groundbreaking paper, "The Atomic Arrangement in Glass," with the remark, "It must be frankly admitted that we know practically nothing about the atomic arrangement in glasses" (Zachariasen, 1932). Zachariasen was just 26 years old when this paper was published, and his work has since become one of the most influential papers in the history of glass. Even more remarkably, this research constituted Zachariasen's sole contribution to the field of glass science. Among the early pioneers of glass science, it was surprisingly common for individuals to have only one or two publications in the field. As with Zachariasen, Arthur Tool's introduction of the fictive temperature concept in 1931 was one of his few published works in glass, and yet it also stands as one of the most influential papers in the field (Tool and Eichlin, 1931). Likewise, the tremendous influence of Walter Kauzmann's sole publication in glass, "The Nature of the Glassy State and the Behavior of Liquids at Low Temperatures" (Kauzmann, 1948) is still felt today.

Another early giant in the field of glass science is Gordon Scott Fulcher, whose 1925 paper, "Analysis of Recent Measurements of the Viscosity of Glasses" (Fulcher, 1925), established the Fulcher equation,

$$
\log \eta(T)=A+\frac{B}{T-T_{0}},
$$

as the de facto standard for describing the temperature dependence of the viscosity of glass-forming liquids, $\eta(T)$, throughout most of the next century. Fulcher proposed this equation empirically based on its ability to reproduce measured viscosity data accurately and its economy of parameters: only three fitting coefficients $-A, B$, and $T_{0}$ - were required to describe $\eta(T)$ curves spanning more than 10 orders of magnitude in viscosity.
Many workers in the field do not realize that Fulcher proposed this equation while he was a staff scientist at Corning Glass Works, where he worked at the Research Laboratory from 1920 to 1934. It is also not commonly known that Fulcher's work in viscosity represented just a small fraction of his distinguished career. The objective of this perspective article is to provide a brief biographical sketch of Gordon Scott Fulcher's remarkable life and contributions, which spanned across many varied disciplines from glass and ceramic sciences to physics, economic theory, and even educational psychology. Throughout his extraordinary career, Fulcher proved himself to be a role model for innovative thinking and leadership.

\section{EARLY BIOGRAPHY OF GORDON SCOTT FULCHER}

Gordon Scott Fulcher (Figure 1) was born in Evanston, IL, USA, on March 21, 1884. His father, Edwin Merrett Fulcher (1840-1924), was the 15th child in a family with 17 children. Edwin was born and raised in London. He moved to Kansas in 1869 and then to Chicago in 1872, where he worked as a bookkeeper for a wholesale dry goods merchant. Edwin worked hard throughout his entire life, retiring only 2 months before his death at the age of 83 years. Gordon's mother, Eliza Scott (1857-1938), was the third child in a family of eight children. She was born in Suffolk, England, and was introduced to Edwin Fulcher during his visit to England in 1876. Eliza Scott moved to Chicago in 1879, where she married Edwin Fulcher. The couple had three children.

The young Fulcher family spent 5 years in South Africa (18871892) but moved back to Chicago so their children could attend school in America. Gordon Fulcher received his secondary education at the Evanston Township High School (1898-1901). He received a scholarship from the Chicago Daily News, which enabled him to attend Northwestern University, where he earned B.S. (1905) and M.A. (1906) degrees in physics. He continued his education at Clark University in Worcester, MA, USA, where he earned a Ph.D. in physics (1910). After finishing his Ph.D., Fulcher became an instructor at Amherst College and then an assistant professor at the University of Wisconsin, where he taught until 


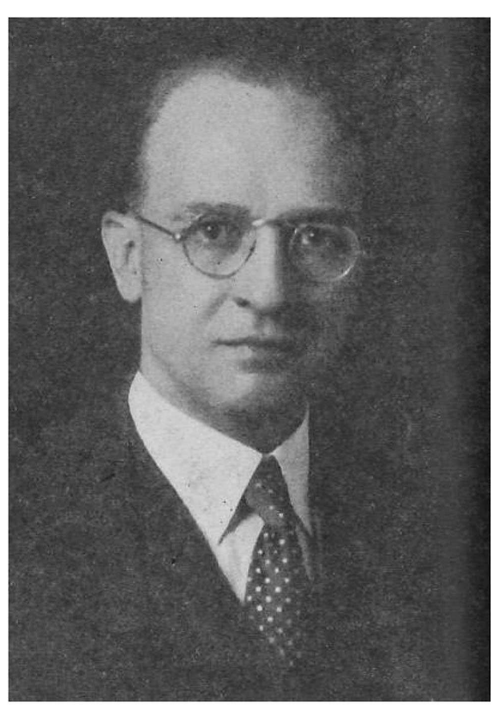

FIGURE 1 | Gordon Scott Fulcher (1884-1971)

1918. Fulcher's early academic research included discovery of the band spectrum of hydrogen in 1911.

During World War I, Fulcher worked on the electrostatic properties of balloon fabrics for the Navy. He joined the Science and Research Division of Signal Corps in Washington, DC, USA, on March 1, 1918. At Signal Corps, Fulcher served as an experimental engineer under Col. R. A. Millikan, where he was put in charge of the development of leak-proof gasoline tanks for airplanes. Fulcher resigned from his work with the military in 1919.

In his personal life, Gordon Fulcher married Louise Morgan in 1913. The couple had a daughter, Anne, born in 1916, and a son, John Scott, born in 1918. Fulcher divorced Louise in 1923 and was later remarried to Hilda Burton Melville in 1931.

\section{CORNING YEARS AND CORHART REFRACTORIES}

Gordon Fulcher joined the Research Laboratory at Corning Glass Works in 1920, where he performed extensive research in the electric melting of glass. Electric melting is especially harsh on the refractory materials used during the melting process, which must withstand very high electrical voltages. Much of Fulcher's career at Corning focused on the development of new refractory materials with higher values of electrical resistivity. Fulcher is credited with the discovery of electrocast refractories, initially based on sillimanite and later incorporating a combination of silica and zirconia to improve the strength of the resulting refractory bricks. After several years of development, Corning spun off the manufacture of electrocast refractories with the founding of the Corhart Refractories Company in Louisville, KY, USA. Corhart began as a joint venture with Hartford Empire, but Corning soon bought out Hartford's share of the company. Production of electrocast refractories at Corhart began in 1927. In 1934, Fulcher left Corning to become the Director of Research at Corhart. After the Research Laboratory at Corhart had been well established, Fulcher retired from the company in 1938 and moved back to Washington, DC,
USA. He continued to act as a consultant for Corhart even after his retirement.

\section{VISCOSITY OF GLASS-FORMING LIOUIDS}

"To the glassmaker, the viscosity of his glass, particularly at the higher temperatures, is of the greatest importance." So begins Gordon Fulcher's groundbreaking paper on the viscosity of glassforming liquids (Fulcher, 1925). Indeed, an accurate understanding of the viscosity of glass-forming liquids is critical for all aspects of industrial glass production, from the initial melting and fining stages to the forming processes and any ensuing relaxation of the low-temperature glassy state. Although he proposed Eq. 1 empirically, at the time of its publication, Fulcher's paper was by far the most thorough treatment of viscosity in the literature, with a careful analysis of experimental viscosity data for a number of different sodium silicate compositions and consideration of a variety of possible equations. The sodium silicate glasses under study also incorporated different concentrations of $\mathrm{MgO}, \mathrm{CaO}, \mathrm{Al}_{2} \mathrm{O}_{3}$, and $\mathrm{B}_{2} \mathrm{O}_{3}$. The Fulcher equation combines a quantitatively accurate description of viscosity over more than 10 orders of magnitude, accomplishing this feat with only 3 adjustable parameters (Scherer, 1992).

Within Corning, Eq. 1 is simply called the Fulcher equation. However, outside of Corning, it is more commonly known as the Vogel-Fulcher-Tammann (VFT) equation. Fulcher's 1925 paper was indeed preceded by a publication from Hans Vogel in 1921. However, Vogel's publication contained $<200$ words of text and presented the equation in a somewhat encrypted form (Vogel, 1921). Although Vogel's paper did not contain any data, he claimed that the equation provided an accurate description of the temperature scaling of viscosity for water, mercury, and oils. After Vogel and Fulcher's publications, the same equation was also proposed by Tammann and Hesse in their 1926 study of the viscous flow of organic liquids (Tammann and Hesse, 1926). Although they cite Fulcher's earlier paper, Tammann and Hesse became aware of his work only after having arrived at the same equation independently. Hence, Eq. 1 is most commonly referred to as the VFT equation, with the exclusion of only the unfortunate Hesse.

For nearly a century since its initial publication, the VFT equation has been the de facto standard for describing the temperature dependence of liquid and supercooled liquid viscosity. Indeed, this equation has been critical for all aspects of industrial glass manufacturing. Despite its ubiquity, there is one notable problem with the equation, viz., the divergence of Eq. 1 as the temperature approaches $T_{0}$. While in practice, this singularity is always avoided by the glass transition, i.e., the structural arrest of the supercooled liquid into the frozen glassy state; it is known to lead to an overprediction of viscosity at temperatures nearing the glass transition (Macedo and Napolitano, 1968; Scherer, 1992; Hecksher et al., 2008). In order to eliminate this systematic error, new equations have been proposed that are derived from fundamental physical considerations and avoid the problem of finite temperature divergence, while still having the same number of adjustable parameters (Avramov and Milchev, 1988; Mauro et al., 2009).

Although Eq. 1 was proposed empirically, many researchers have tried to ascribe physical meaning to the various fitting 
parameters, particularly the $T_{0}$ parameter at which the VFT equation predicts a dynamic divergence. Through the connection between viscosity and configurational entropy proposed by Adam and Gibbs (1965), the $T_{0}$ parameter of the VFT equation is often associated with the Kauzmann temperature $T_{\mathrm{K}}$, at which the configurational entropy of the supercooled liquid would become zero by extrapolating from higher temperature (Kauzmann, 1948). In other words, the divergence of viscosity at $T_{0}$ predicted by the VFT equation would correspond to a vanishing of configurational entropy as suggested by Kauzmann. As a way to avoid this so-called "entropy catastrophe," Gibbs and DiMarzio (1958) proposed the existence of an ideal thermodynamic glass transition at $T_{\mathrm{K}}$. While highly debated in the literature, subsequent work by Stillinger has shown convincing theoretical arguments for why the concept of an entropy catastrophe at $T_{\mathrm{K}}$ is unphysical (Stillinger, 1988). The questions of dynamic divergence and the Kauzmann entropy catastrophe are discussed in much greater detail in a recent review article by the author (Mauro, 2011).

\section{SCIENTIFIC ABSTRACTING}

From 1919 to 1920, Fulcher served as a scientific associate with the National Research Council, where he prepared rules for the abstracting of authors' submissions. He also served as the abstract editor of Astrophysical Journal and Physical Review. While at Corning, Fulcher served as the managing editor of Physical Review (1923-1925) and introduced the practice of distributing programs and abstracts at American Physical Society meetings. Fulcher's new method of abstracting was adopted for the subject index of Science Abstracts. In May, 1924, Fulcher traveled to Brussels, Belgium, as a representative of the National Research Council to attend a meeting of the Committee on Intellectual Cooperation of the League of Nations. The committee included such notable scientists as H. A. Lorentz, M. Curie, and P. Langevin. The committee voted unanimously to recommend that all articles published by scientific journals should be preceded by abstracts, following the rules adopted by Physical Review under Fulcher's leadership. Upon finishing his tenure at Physical Review, the American Physical Society passed a resolution expressing appreciation "for introducing an abstracting system, which has proved a distinct contribution to bibliographic method, and for greatly improving the quality of papers appearing in the Physical Review, by an immense amount of detailed editorial work."

\section{ECONOMICS AND METACOGNITION}

Fulcher held self-described liberal views on politics and religion and had an intense interest in economic theory, educational psychology, and the great social and moral problems facing the world. These problems were the main focus of his research after retirement from the ceramics industry and his subsequent move to Washington. He initially focused on the cause of economic depressions, publishing a series of papers on prosperity and underspending in which he argued for a tax on underspending analogous to a sales tax on spending. As a result of his research, Fulcher "became convinced that progress in solving social problems is greatly hindered by the inability of political and other leaders to think soundly." This led Fulcher to publish two short books in the field of metacognition. His 1948 book, Better Thinking for
Better Living, was published by Edwards Brothers, and in 1965, Northwestern University Press published his book on Common Sense Decision-Making.

\section{CONCLUSION}

Even several decades after his death on October 21, 1971, the legacy of Gordon Scott Fulcher lives on. His paper on the viscosity of glass-forming liquids is one of the most influential papers ever published in the field of glass science. The empirical equation that he proposed has led to great debates surrounding the dynamics of supercooled liquids at low temperatures, the existence of an ideal glass transition, and the connection between the thermodynamics and kinetics of supercooled liquids and glasses. Fulcher's pioneering work on electrocast ceramics and electrical melting of glass is still the basis for much of our glass and ceramic engineering technology today. More broadly, the system of modern abstracting proposed by Fulcher is now so ubiquitous that we may take for granted the fact that someone had to invent it. The many years of thought that Fulcher put into developing his system of abstracting at the Physical Review and other journals served as a precursor for the electronic database systems that are used today.

Fulcher's interest extended well beyond the hard sciences, as evidenced by his publications in the fields of economics and psychology. Fulcher's undergraduate alma mater, Northwestern University, has even honored Fulcher with a chaired professorship in his name: the Gordon Fulcher Professor in Decision-Making at the Weinberg College of Arts and Sciences. Fulcher was a pioneering thought leader in both technical and non-technical fields who successfully transformed his innovative thinking into action that has changed the world. We should be proud to claim Fulcher as our very own Renaissance man of glass science.

Fulcher's publications comprise 21 in physics (including his one publication on the viscosity of glass-forming liquids), 5 papers on scientific abstracting, 2 papers on electrocast refractories, 7 publications on economics, and 3 papers on other miscellaneous topics. Fulcher holds 14 U.S. patents and has published two books. He was a Fellow of the American Physical Society, the American Ceramic Society, and the American Association for the Advancement of Science.

\section{ACKNOWLEDGMENTS}

All of the biographical information and most of the inspiration for this article comes from a tribute to Gordon Scott Fulcher published in the American Ceramic Society Bulletin ["Gordon Scott Fulcher," Am. Ceram. Soc. Bull. 23 (2) 62-64, 1944] and from an article published by G. W. Scherer in the Journal of the American Ceramic Society (Scherer, 1992). I am grateful to N. F. Borrelli of Corning Incorporated for encouraging me to write this perspective article to share the story of Gordon Scott Fulcher.

\section{REFERENCES}

Adam, G., and Gibbs, J. H. (1965). On the temperature dependence of cooperative relaxation properties in glass-forming liquids. J. Chem. Phys. 43, 139-146. doi:10.1063/1.1696442

Avramov, I., and Milchev, A. (1988). Effect of disorder on diffusion and viscosity in condensed systems. J. Non-Cryst. Solids 104, 253-260. doi:10.1016/00223093(88)90396- 1 
Fulcher, G. S. (1925). Analysis of recent measurements of the viscosity of glasses. J. Am. Ceram. Soc. 8, 339-355. doi:10.1021/jf803278b

Gibbs, J. H., and DiMarzio, E. A. (1958). Nature of the glass transition and the glassy state. J. Chem. Phys. 28, 373-383. doi:10.1063/1.1744141

Hecksher, T., Nielsen, A. I., Olsen, N. B., and Dyre, J. C. (2008). Little evidence for dynamic divergences in ultraviscous molecular liquids. Nat. Phys. 4, 737-741. doi:10.1038/nphys 1033

Kauzmann, W. (1948). The nature of the glassy state and the behavior of liquids at low temperatures. Chem. Rev. 43, 219-256. doi:10.1021/cr60135a002

Macedo, P. B., and Napolitano, A. (1968). Inadequacies of viscosity theories for $\mathrm{B}_{2} \mathrm{O}_{3}$. J. Chem. Phys. 49, 1887-1895. doi:10.1063/1.1670321

Mauro, J. C. (2011). Through a glass, darkly: Dispelling three common misconceptions in glass science. Int. J. Appl. Glass Sci. 2, 245-261. doi:10.1111/j.2041-1294. 2011.00069.x

Mauro, J. C., Yue, Y. Z., Ellison, A. J., Gupta, P. K., and Allan, D. C. (2009). Viscosity of glass-forming liquids. Proc. Natl. Acad. Sci. U.S.A. 106, 19780-19784. doi:10.1073/pnas.0911705106

Scherer, G. W. (1992). Editorial comments on a paper by Gordon S. Fulcher. J. Am. Ceram. Soc. 75, 1060-1062. doi:10.1111/j.1151-2916.1992.tb05537.x

Stillinger, F. H. (1988). Supercooled liquids, glass transitions, and the Kauzmann paradox. J. Chem. Phys. 88, 7818-7825. doi:10.1063/1.454295

Tammann, G., and Hesse, W. (1926). Die abhängigkeit der viscosität von der temperatur bei unterkühlten flüssigkeiten. Z. Anorg. Allg. Chem. 156, 245-257. doi:10.1002/zaac.19261560121
Tool, A. Q., and Eichlin, C. G. (1931). Variations caused in the heating curves of glass by heat treatment. J. Am. Ceram. Soc. 14, 276-308. doi:10.1111/j.1151-2916. 1931.tb16602.x

Vogel, H. (1921). Das temperatur-abhängigkeitsgesetz der viscosität von flüssigkeiten. Phys. Z. 22, 645-646.

Zachariasen, W. H. (1932). The atomic arrangement in glass. J. Am. Chem. Soc. 54, 3841-3851. doi:10.1021/ja01349a006

Conflict of Interest Statement: The author declares that the research was conducted in the absence of any commercial or financial relationships that could be construed as a potential conflict of interest.

Received: 02 October 2014; accepted: 20 October 2014; published online: 03 November 2014.

Citation: Mauro JC (2014) Gordon Scott Fulcher: Renaissance man of glass science. Front. Mater. 1:25. doi: 10.3389/fmats.2014.00025

This article was submitted to Glass Science, a section of the journal Frontiers in Materials.

Copyright $(2014$ Mauro. This is an open-access article distributed under the terms of the Creative Commons Attribution License (CC BY). The use, distribution or reproduction in other forums is permitted, provided the original author(s) or licensor are credited and that the original publication in this journal is cited, in accordance with accepted academic practice. No use, distribution or reproduction is permitted which does not comply with these terms. 